Gut, 1984, 25, 1279-1282

\title{
Evidence of pudendal neuropathy in patients with perineal descent and chronic straining at stool
}

\author{
E S KIFF, P R H BARNES, AND M SWASH \\ From St Mark's Hospital, London
}

SUMMARY In 17 women with chronic constipation, and abnormal perineal descent on straining at stool, there was more severe neurogenic damage to the external anal sphincter muscle and to its pudendal innervation in those patients with a long history than in those with a short history. These results suggest that recurrent trauma to the pudendal nerves can occur during perineal descent, and that this can lead to denervation and weakness of the external anal sphincter muscle.

Between $30 \%$ and $66 \%$ of patients with faecal incontinence give a long history of excessive straining at stool. ${ }^{12}$ It has been suggested that prolonged straining during defaecation may cause perineal descent $;^{3}$ this in turn may result in recurrent injury to the pudendal nerves and so to progressive denervation atrophy of the external anal sphincter muscle supplied by these nerves. The activity of this muscle is reduced in incontinent patients as has been shown by anorectal manometry and electromyography (EMG). ${ }^{24}$ Using single fibre EMG, Neill and Swash ${ }^{5}$ found an increased motor unit fibre density in the external anal sphincter muscle of incontinent patients. This increased fibre density was consistent with the histological evidence of reinnervation in biopsies of this muscle taken from similar patients. ${ }^{367}$ Henry, Parks, and Swash ${ }^{7}$ found muscle fibre hypertrophy in the external anal sphincter muscle of both continent and incontinent patients with abnormal degrees of perineal descent. They suggested that this hypertrophy represents compensation for the loss of muscle fibres caused by pudendal nerve damage induced by the perineal descent.

We have reported an increased terminal motor latency in the pudendal nerves after stimulation of these nerves at the level of the ischial spine in patients with neurogenic faecal incontinence. ${ }^{1}$ This work supports our suggestion that the site of damage to this nerve may be at the point where it passes beneath the sacrospinous ligament. ${ }^{3}$ We have now tested this hypothesis that the pudendal nerves may be damaged in patients with perineal descent and

Address for correspondence: Dr M Swash, Neurological Department, The London Hospital, London E1 1BB.

Received for publication 29 January 1984 chronic constipation by direct measurement of pudendal nerve conduction.

\section{Methods}

\section{PATIENTS}

Seventeen women with a history of chronic constipation were studied. All had perineal descent on straining. Eleven patients, aged 34-70 years (mean $48 \cdot 1 \pm 9 \cdot 7$ years) had been intermittently straining at stool for between 20 and 50 years (mean 26 years), whereas in the other six patients aged 22-25 years (mean $23.8 \pm 1.5$ years) the history of straining was of 10 years or less (mean 6.8 years). The mean frequency of straining per week was similar in both groups; 6.0 and 6.3 respectively. None of the six young patients was parous and none had had pelvic surgery, whereas nine of the group with a long history of straining were parous and two of these women gave a history of difficult labour. In addition three patients in this group had had a hysterectomy and a further three patients had had other pelvic surgery (colectomy with ileorectal anastomosis for constipation, pelvic floor repair, rectopexy).

All 17 patients were examined clinically, by anorectal manometry and by EMG methods. The results were compared with those obtained in our laboratory in normal subjects of similar age and sex.

\section{PERINEAL DESCENT MEASUREMENT}

Measurements were made using a graduated latex cylinder held against the anal verge and moving within a steel frame pressed against the ischial tuberosities. $^{7}$ Measurements werc taken of the position of the perineum relative to the ischial tuberosities, both at rest and during a maximal straining effort. 
ANORECTAL MANOMETRY

Measurements of resting tone and maximal voluntary contraction pressures within the anal canal were made using a small water filled balloon connected via a transducer to an ultraviolet recording device as described previously. ${ }^{2}$

\section{ELECTROMYOGRAPHY}

Concentric needle EMG was used to measure the rectified, integrated activity recorded within the external anal sphincter muscle during one second. The activity at rest, during a straining effort and during a maximal voluntary contraction was measured. ${ }^{1}$ The fibre density within the external anal sphincter muscle was determined using single fibre EMG. ${ }^{8}$ The normal fibre density in this muscle is $1 \cdot 5 \pm 0 \cdot 16$, but this increases slightly after age 65 years. ${ }^{5}$

\section{PUDENDAL NERVE TERMINAL MOTOR LATENCY} MEASUREMENT

This method has been described in detail elsewhere. ${ }^{1}$ The device used consists of a rubber finger stall having two stimulating electrodes at its tip and two surface electrodes for recording mounted at its base. With the device placed on the index finger and inserted into the rectum the pudendal nerve is stimulated transrectally at the level of the ischial spine and the latency of the response in the external anal sphincter muscle recorded by the surface electrodes is measured on the paper printout of the EMG apparatus. The mean terminal motor latency in 28 normal subjects, aged 15-73 years (mean $44 \cdot 1$ years ) was $2.0 \pm 0.3$ msec. ${ }^{1}$

In all cases the results obtained in the constipated patients have been compared with those obtained from normal subjects. 2 In addition we have compared the results of the six patients with a short history of straining with those of the eleven patients with a long history of straining.

\section{Results}

\section{PERINEAL DESCENT MEASUREMENT}

There was no significant difference in the position of the pelvic floor at rest or during straining in the two groups of women. In the patients with a short history of straining the position at rest ranged from $2.75 \mathrm{~cm}$ above to $1.0 \mathrm{~cm}$ below the level of the ischial tuberosities (mean $1 \cdot 0 \pm 1.3 \mathrm{~cm}$ above) and the position during a maximal straining effort ranged from $0.5 \mathrm{~cm}$ above to $3.25 \mathrm{~cm}$ below this level (mean $1 \cdot 0 \pm 1.7 \mathrm{~cm}$ below). The distances moved during straining ranged from $1 \cdot 25-2.5 \mathrm{~cm}$ (mean $2 \cdot 0 \pm .05 \mathrm{~cm}$ ). The corresponding figures for patients with a long history of straining were as follows: level at rest, $2.5 \mathrm{~cm}$ above $-0.5 \mathrm{~cm}$ below (mean $0.9 \pm 1.0 \mathrm{~cm}$ above); straining level, $0.6 \mathrm{~cm}$ above $-3.5 \mathrm{~cm}$ below (mean $1.3 \mathrm{~cm}$ below \pm 1.5 $\mathrm{cm}$ ); perineal descent, range $1 \cdot 0-4.75 \mathrm{~cm}$ (mean $2 \cdot 4 \pm 1 \cdot 1 \mathrm{~cm})$. The mean resting level of the constipated group as a whole was $1 \cdot 0 \pm 1 \cdot 1 \mathrm{~cm}$ above the level of the ischial tuberosities, a result significantly lower $(p<0.001)$ than that found by Henry et $a l^{8}$ in one hundred and three normal subjects (mean resting level $2.5 \pm 0.6 \mathrm{~cm}$ ). Similarly the mean level during a straining effort in the constipated group as a whole (mean $1.2 \pm 1.6 \mathrm{~cm}$ below) was significantly lower $(p<0.001)$ than that of normal subjects (mean $0.9 \pm 1.0 \mathrm{~cm}$ above). The distance travelled by the perineum during a straining effort was significantly greater in the constipated group (mean $2 \cdot 2 \pm 1 \cdot 0 \mathrm{~cm})(0.04>\mathrm{p}>0.01)$ than normal (mean $1.6 \mathrm{~cm}$ ).

\section{ANORECTAL MANOMETRY}

In the patients with a short history of straining the resting tone ranged from $73-115 \mathrm{~cm}$, mean $92 \cdot 6 \pm 17.2 \mathrm{~cm}$ water (normal range 60-100 cm water). Maximal voluntary contraction pressures in this group ranged from $60-160 \mathrm{~cm}$, mean $103 \cdot 3 \pm 51.3 \mathrm{~cm}$ water (normal range $80-200 \mathrm{~cm}$ water). In the patients with a long history of straining the resting tone ranged from $28-120 \mathrm{~cm}$, mean $91.7 \pm 37.0$ water. Maximal voluntary contraction pressures ranged from $40-200 \mathrm{~cm}$, mean $83 \cdot 2 \pm 48 \cdot 0$ water.

\section{CONCENTRIC NEEDLE EMG DURING STRAINING}

AND VOLUNTARY CONTRACTION OF THE EXTERNAL ANAL SPHINCTER MUSCLE.

The sum of the rectified EMG acitivity during one second of maximal voluntary contraction in the external anal sphincter muscle was reduced in the group with a long history of straining, mean $26 \cdot 0 \pm 10 \cdot 6 \mu \mathrm{Vsec}$ (range $16-40 \mu \mathrm{Vsec}$ ). The values obtained from 29 normal subjects ranged from 40-130 $\mu$ Vsec mean 67.0 $\pm 21 \mu$ Vsec. $^{1}$ In the normal external anal sphincter muscle the EMG activity during a straining effort is usually less than the resting activity ${ }^{4}$ but in all our constipated patients the EMG activity during straining (range 1-24 $\mu \mathrm{Vsec}$, mean $12 \cdot 7 \pm 12 \cdot 1 \mu \mathrm{Vsec}$ ) was increased over resting levels (range $1-6 \mu$ Vsec, mean $2 \cdot 7 \pm 2 \cdot 1$ $\mu \mathrm{Vsec})$. In some patients with a long history of straining this activity was of a similar level to that seen during a maximal voluntary contraction.

FIBRE DENSITY

The fibre density in the patients with a short history of straining ranged from $1 \cdot 1$ to $1 \cdot 3$ (mean $1 \cdot 2$ ), a 
value within the normal range. In the patients with a long history of constipation the fibre density was increased; range $1 \cdot 2-2 \cdot 6$, mean $1 \cdot 8 \pm 0 \cdot 6$. The fibre density was abnormally high in five of these 11 patients.

PUDENDAL NERVE TERMINAL MOTOR LATENCY The pudendal nerve terminal motor latency in the patients with a short history of straining ranged from $1.8-2.3 \mathrm{msec}$ (mean $2 \cdot 0 \pm 0.2 \mathrm{msec}$ ) on the right and $1.9-2.5 \mathrm{msec}$ (mean $2.1 \pm 0.2 \mathrm{msec}$ ) on the left; the mean value derived from both sides was $2 \cdot 1 \pm 0 \cdot 3$ msec. These values are within the normal range $1.4-2.6 \mathrm{msec}$ (mean $2.0 \pm 0.3 \mathrm{msec}$ ) found in 28 normal subjects. ${ }^{1}$ In the patients with a long history of straining the pudendal nerve terminal motor latency ranged from $2 \cdot 2-3 \cdot 4$ msec (mean $2 \cdot 7 \pm 0 \cdot 4$ msec) on the right and $2 \cdot 0-3 \cdot 8 \mathrm{msec}$ (mean $2 \cdot 8 \pm 0 \cdot 6$ $\mathrm{msec})$ on the left. The mean value $(2 \cdot 8 \pm 0.5 \mathrm{msec})$ was significantly $(\mathrm{p}<0.01)$ greater than normal when tested by the Wilcoxon's rank sum test.

\section{Discussion}

Perineal descent is recognised clinically by ballooning of the perineum during a straining effort. It is commonly seen in patients with neurogenic faecal incontinence though whether it represents cause or effect is unclear. Obviously, bulging of the pelvic floor when the intra-abdominal pressure is transiently raised is a sign of weakness of the pelvic floor musculature. Patients with the descending perineum syndrome, however, may have marked perineal descent with normal faecal continence or, as in the patients studied here, they may be constipated.

The descending perineum syndrome was initially defined as descent of the anorectal angle, as assessed by a radiographic technique. ${ }^{9}$ Henry's method, ${ }^{7}$ as used in this study, is simpler and safer to perform. We have measured the position of the perineum at rest and the extent of descent on straining. There was no significant difference in either of these values between the two constipated groups, but the mean position both at rest and during a straining effort was significantly lower in the constipated group as a whole when compared with normal subjects. In addition the amount of perineal descent on straining was significantly greater than that of the normal subjects. Descent of the perineum represents a potential stretch injury to the pudendal nerves. The extent of that injury may depend both on the frequency with which the straining activity occurs as well as the number of years over which it continues. Our data suggest that the latter two parameters are more important than the extent of perineal descent, either at rest or on straining, in the aetiology of pudendal neuropathy. These data also confirm the importance of puborectalis and other pelvic floor muscles and the relative unimportance of the external anal sphincter muscle in maintaining pelvic floor position as those patients with a long history of straining have EMG evidence of damage to the external anal sphincter muscle yet no significantly greater perineal descent than patients with a short history of straining.

The differences in fibre density and pudendal nerve latency between patients with a short history and those with a long history of straining clearly point to the presence of pudendal neuropathy in the latter group. This results in neurogenic damage to the external anal sphincter muscle as shown by EMG. These patients remain constipated because they have an abnormal, counter productive increase in activity in both puborectalis and the external anal spincter muscle on straining and hence maintain the anorectal angle despite bulging the perineum. The cause of this abnormal pattern of muscle contraction is unknown.

These data support the hypothesis that perineal descent may lead to pudendal neuropathy. This takes many years to develop and seems to be related more to the number of years that perineal descent has been abnormal than to the degree of descent achieved. This is consistent with the suggestion that recurrent trauma during perineal descent damages the pudendal nerve as it passes under the sacrospinous ligament. Measures to prevent abnormal patterns of defaecation may thus prevent the later development of denervation and weakness of the pelvic floor musculature.

ESK and PRHB were supported by the St Mark's Hospital Research Foundation.

\section{References}

1 Kiff ES, Swash M. Slowed conduction in the pudendal nerves in idiopathic (neurogenic) faecal incontinence. Br J Surg 1984. (In press.)

2 Neill ME, Parks AG, Swash M. Physiological studies of the pelvic floor in idiopathic faecal incontinence and rectal prolapse. Br J Surg 1981; 68: 531-6.

3 Parks AG, Swash M, Urich H. Sphincter denervation in anorectal incontinence and rectal prolapse. Gut 1977; 18: 656-65.

4 Kerremans R. Morphological and physiological aspects of anal incontinence and defaecation. Brussels: Editions Arscia S A, 1969.

5 Neill ME, Swash M. Increased motor unit fibre density 
in the external anal sphincter muscle in anorectal incontinence: a single fibre EMG study. J Neurol Neurosurg Psychiatry 1980; 43: 343-7.

6 Beersiek F, Parks AG, Swash M. Pathogenesis of anorectal incontinence: a histometric study of the anal musculature. J Neurol Sci 1979; 42: 111-27.

7 Henry MM, Parks AG, Swash M. The pelvic floor musculature in the descending perineum syndrome. $\mathrm{Br}$ J Surg 1982; 69: 470-2.

8 Stalberg E, Trontelj JV. Single fibre electromyography. Woking: Mirvalle Press, 1979.

9 Parks AG, Porter NH, Hardcastle JD. The syndrome of the descending perineum. Proc R Soc Med 1966; 59: 477-82. 